Journal of Research in Nursing

Vol. 1, No. 1, 2015

Print ISSN 2244-2723

University of Cebu

Cebu City, Cebu, Philippines

\title{
Research Portfolio in a University-based Nursing School
}

\author{
Jonnette B. Labrador \\ Mauro Allan P. Amparado
}

\section{Abstract}

This study analyzed the research portfolio conducted by the student nurses of the University of Cebu Banilad from 2007 to 2009. Furthermore, it determined the quality of the research portfolio of the same years and students. The findings served as the bases for a proposed research plan.

This study utilized the descriptive-analytical design. A content analysis was employed to make a systematic examination of the research portfolio to ascertain the profile and the quality of the researches made. Specifically, this study used a researcher-made checklist-questionnaire in the gathering of data to determine the profile and the quality of the research projects.

The study was conducted at the College of Nursing, University of Cebu Banilad. There were six Clinical Instructors who evaluated the research projects. Four of the Clinical Instructors are employees of the University of Cebu Banilad, while the other two are employees of the University of Cebu Lapu-Lapu \& Mandaue.

Based on the key findings of the study, the profile of the research portfolio was found to be: generally univariate and bivariate; health-related; descriptive-correlational; school-based 
projects; utilized respondents; employed simple random sampling; uses questionnaires; descriptive analysis; and education-thrust studies. On the other hand, the quality of the research portfolio from 2007 to 2009 had evolved from partially proficient towards proficient.

Recommended citation: Labrador, J. B. \& Amparado, M. A. P. (2015). Research Portfolio in a University-based Nursing School. Journal of Research in Nursing, 1(1), 90-100. 